\title{
Mudar para permanecer o mesmo: marcas de um discurso de autolegitimação jornalística na história
}

Bruno Souza Leal

Nuno Manna

Phellipy Jácome

Resumo: Este artigo busca caracterizar indícios do discurso de autolegitimação de mídias informativas e as relações que ele estabelece com a historicidade e demais dimensões temporais presentes no jornalismo. Nesse esforço de caracterização, recupera-se um conjunto de falas institucionais de agentes jornalísticos brasileiros sobre si mesmos, especialmente aquelas vinculadas às reformas editoriais de jornais diários impressos na chamada modernização da imprensa. Tal como em outros textos de caráter normativo, percebemos uma simplificação da historicidade dos fenômenos jornalísticos, na medida em que esse discurso se baseia na (re) afirmação dos mesmos valores e princípios na história.

Palavras-chave: jornalismo; historicidade; discurso de autolegitimação.

Abstract: Change to remain the same: outlines of a discourse of journalistic self-legitimation in history

- This paper aims to characterize evidences of informative media's self-legitimation speech and the relations it establishes with the historicity and other temporal dimensions present in journalism. This characterization effort recovers a set of institutional statements made by Brazilian journalistic agents about themselves, particularly those linked to the editorial reforms of daily newspapers in the so-called modernization of the press. As in other normative texts, we notice that there is an oversimplification of the historicity of the journalistic phenomena, since this speech is based on the (re)affirmation of the same values and principles in history.

Keywords: journalism; historicity; self-legitimation speech. 


\section{Introdução}

Em junho de 1808, logo na Introdução do seu Correio Braziliense, Hipólito da Costa trata de expor aquelas que seriam as principais funções dos redatores de folhas públicas. Entre elas, destaca-se o seu caráter eminentemente didático, na medida em que as luzes do conhecimento, proporcionadas pela natureza, pela arte e pela educação, devem ser responsáveis por combater as trevas e a "illuzaõ". Sustenta Hipólito que "ninguém mais útil pois do que aquele que se destina a mostrar, com evidência, os acontecimentos do presente, e desenvolver as sombras do futuro" (COSTA, [1808] 2001, p. A2). Assim, a razão de ser e a legitimidade social do jornal, segundo Hipólito, é fundamentada em um princípio que organiza o modo de conceber e lidar com a realidade e o associa a uma forma de articulação entre o fazer no presente e seu sentido para o futuro.

Não por acaso, os trabalhos dos escritores de jornal, "munidos de uma crítica saã e censura adequada" (COSTA, [1808] 2001, p. A2), formula Hipólito, ao mesmo tempo devem representar os fatos do momento e as reflexões sobre o passado, bem como oferecer "solidas conjecturas sobre o futuro". O jornal, nesse sentido, parece se oferecer como, para usar termos atuais, um dispositivo (ANTUNES E VAZ, 2006; MOUILLAUD, 2002) de captura de um presente que materializa modos de entendimento sobre esse tempo e, por consequência, sobre o que passou e o que virá.

Mais de duzentos anos mais tarde, em 2011, o Grupo Globo lança os seus "Princípios Editorais", documento que pretende expor um conjunto de características que deverão guiar a execução dos produtos jornalísticos desse conglomerado midiático. Para tanto, definese o jornalismo como uma atividade produtora de conhecimento, a ser posteriormente aprofundado pelo próprio jornalismo, por cientistas sociais e especialmente pela História. Essa relação com a História se articula, aparentemente de modo paradoxal, com a agilidade típica dos fazeres e do saber jornalísticos. Se a "notícia tem pressa", como caracterizam os Princípios..., "é a celeridade com que traça o primeiro retrato dos fatos que ao mesmo tempo dá utilidade à produção jornalística e justifica suas lacunas" (Grupo Globo, 2011, online).

Enquanto para o Correio Braziliense o presente e seus acontecimentos são o caminho de construção do futuro, nos Princípios... parece haver uma aceleração do tempo, um reconhecimento de que os fatos de agora (e o modo jornalístico de apreendê-los) logo serão um passado a ser julgado à luz do que e daqueles que vierem. Em que pese essa diferença, não se pode deixar de notar que essas duas falas sobre "o que é o jornalismo" guardam curiosas semelhanças. Ambas compartilham uma concepção do jornalismo como uma espécie de "história possível no presente", calcada na sua capacidade de lidar com a realidade dos fatos, à espera do futuro. Em outras palavras: existe, em ambos, um falar sobre uma realidade destinada a ser histórica - mais precisamente na medida de uma concepção moderna de história (KOSELLECK, 2006). 
É significativo que essa relação temporal legitimadora de um papel do jornalismo seja encontrada em textos que se vinculam a contextos históricos e a produtos midiáticos tão distintos e, em vários aspectos, incomparáveis. Afinal, entre outras coisas, o Correio... apresentava um jornalismo enciclopédico (HOHLFELDT e OLIVEIRA, 2008), era editado e impresso fora do país, definia-se também com um "Armazém Literário", possível de ser compilado em formato de livro, com claras marcas de autoria. Esse jornalismo encontra poucas similitudes em relação ao que é apresentado por um grupo empresarial que detêm diferentes companhias e produtos midiáticos, numa escrita que se oferece, por vezes, como impessoal e estrategicamente observante. Assim, as diferentes materialidades, narrativas, formatos e textualidades que separam e distinguem o jornal do século XIX e os produtos multimidiáticos do século XXI se apresentam como índices claros da historicidade dos fenômenos jornalismos, de complexas relações de continuidade e mudanças vividas ao longo do tempo.

Muitas outras manifestações discursivas como essas emergem na história, especialmente em momentos de reforma editorial, pois, como se sabe, ao longo do século XX e nesse início de século XXI, diferentes jornais e produtos jornalísticos brasileiros passam por processos de modernização, por meio dos quais buscam, de algum modo, responder e mesmo se antecipar às transformações históricas em curso. Ao mesmo tempo, elas procuram caminhos mais eficazes de comunicação com os interlocutores dos jornais e, com isso, de consolidação de sua identidade.

Tendo isso em vista, objetivamos enfrentar aqui a contradição entre um discurso que se afirma na tentativa de desistoricização de valores e processos jornalísticos e as relações temporais nele marcadas. Nesse nosso esforço de caracterização, recuperamos um conjunto de falas institucionais de agentes jornalísticos brasileiros sobre si mesmos, de diferentes momentos históricos, tanto para buscar pistas desse discurso de autolegitimação quanto das contradições que apresenta. Em função dos limites formais estabelecidos para este artigo, essa revisão se faz, em certa medida, de modo indicial (GINZBURG, 1990; BRAGA, 2008), ou seja, menos por um inventário exaustivo e linear dessas falas do que pela reunião de pistas que promovem uma visualização significativa desse discurso e de suas contradições.

\section{Sob o signo do mesmo}

Uma das características comuns que podemos observar em distintos discursos autorreferenciais das mídias informativas pela história é justamente a relação que se estabelece - ou que se pretende estabelecer - com a realidade e com o presente. Nesse ponto, podemos perceber uma recorrência histórica de um argumento que tende a tomar os fatos como fragmentos externos à ação do jornal ou do jornalista, como se fosse possível ao jornalismo duplicar essa realidade nas histórias que conta. Temos, nesse sentido, a ideia de uma realidade extralinguística, fixa, "natural", que ainda que não possa ser abarcada por completo, deve ser purificada (LATOUR, 1994) pelas técnicas jornalísticas para ser 
representada da forma mais fiel possível. Desse modo, a noção de objetividade, ainda que muito criticada atualmente, continua, como ressalta Ribeiro (2006, p.11), como uma das grandes responsáveis pela acolhida que o jornalismo tem e, por isso, o discurso autorreferente dos jornais ainda guarda as marcas de um resguardo da representação objetiva. Nas últimas décadas, algumas outras palavras, como independência, honestidade, imparcialidade, isenção, vem sendo utilizadas, em complementação ou substituição às já desgastadas demais, mas a base do argumento que pretende estancar a realidade permanece o mesmo. Retomemos os Princípios..., por exemplo:

Antes, costumava-se dizer que o jornalismo era a busca pela verdade dos fatos. Com a popularização confusa de uma discussão que remonta ao surgimento da filosofia (existe uma verdade e, se existe, é possível alcançá-la?), essa definição clássica passou a ser vítima de toda sorte de mal-entendidos. [...] Não se trata aqui de enveredar por uma discussão sem fim, mas a tradição filosófica mais densa dirá que a verdade pode ser inesgotável, inalcançável em sua plenitude, mas existe; e que, se a objetividade total certamente não é possível, há técnicas que permitem ao homem, na busca pelo conhecimento, minimizar a graus aceitáveis o subjetivismo (Grupo Globo, 2011, s/p).

Nesse fragmento, é possível perceber que a linha argumentativa é traçada a partir da ideia de que, em algum ponto da história, houve uma série de mal-entendidos que terminaram por minar o que seria uma definição clássica do jornalismo: "a busca pela verdade dos fatos". Isso se deveu, segundo o Grupo Globo, por conta de simplificações que, no cúmulo, chegam a questionar, até mesmo, a possibilidade de existir alguma verdade objetiva. Ao posicionar-se contrariamente ao que entendem ser uma "simplificação", os Princípios... reafirmam a impossibilidade de se alcançar uma plena objetividade, mas reforçam a ideia de uma realidade bipartida, reproduzível, buscando técnicas para minimizar suas contaminações. A afirmação da importância do conhecimento jornalístico se dá, portanto, pela retomada, no presente e para o futuro, de valores já existentes, mas desviados por gerações anteriores. Instaura-se, então, na base da argumentação, uma contraposição entre esses valores, como ideais, e os processos e modos como eles são apreendidos, transformados e materializados historicamente. A reafirmação desses ideais é, curiosamente, um esforço de continuidade e de ruptura com o passado.

O argumento exposto em 2011 é bastante semelhante ao elaborado, 26 anos antes, pela Folha de S. Paulo. Em 27 de julho de 1985, o diário apresenta aos seus leitores e anunciantes o seu novo projeto editorial, intitulado Projeto Folha. No caderno Ilustrada, o jornal pontua algumas características que devem orientar sua empreitada, marcando a maneira como entende o jornalismo e sua relação com o mundo. No texto "A crítica da crítica da objetividade", o diretor de Redação Otavio Frias Filho afirma: 
Houve uma época em que se acreditava na objetividade do jornalismo. Isso aconteceu na idade de ouro dos jornais, antes da popularização do rádio e até da TV. Bastava que o jornal ou o jornalista tivesse "boas intenções" - era o que se pensava - para que o registro dos fatos fosse uma imagem perfeita do seu próprio conteúdo (FRIAS Fo., 1985, p. 41).

O recurso utilizado na construção argumentativa da Folha é bastante similar ao empregado pelo Grupo Globo. Há uma rememoração do passado para dizer da crença na objetividade no jornalismo. Essa seria, como aponta o jornal, a "objetividade clássica" (FOLHA, 1985, p. 41), que teria sofrido muitas críticas, principalmente a partir dos anos 1960, na medida em que, diz o diário, "há muitas maneiras de ver o mesmo fato e o jornalista tem que optar por um delas" (idem). Tais críticas teriam sido as responsáveis por criar a imprensa alternativa no país e a ideia de que a única objetividade possível pela "imprensa do establishment" era apenas a de um jogo de aparências.

Contrário a esse movimento, afirma Frias, a "experiência recente da Folha se enquadra numa espécie de crítica à crítica da objetividade" (idem). O Projeto Folha deveria recuperar, assim, "a dimensão factual do mundo que o jornal registra, factual no sentido de ser verificável fora da linguagem" (idem). Assim sendo, o que o jornal postula é uma separação possível e viável entre linguagem e realidade, entre um mundo das regularidades e outro, que se transforma. Ou seja, a crença numa separação radical entre linguagem e mundo - e entre sujeito e objeto - é reforçada e defendida pelo jornal como a base da relação que ele estabeleceria com a realidade. Tal argumento é o mesmo que sustenta a noção de jornalismo como "o espelho do mundo", largamente utilizada pela imprensa pelo menos desde o século XIX (VOS, 2011) - metáfora que, 25 anos depois, intitula o editorial da Folha que inaugura a sua reforma editorial em 2010 (FOLHA, 2010), quando o diário se autodenomina "o jornal do futuro".

É importante destacar que, em 1985, a Folha descreve a possibilidade de existência de realidades nas quais, segundo o jornal, não haveria experiência factual (só existiram, portanto, na linguagem), e em que a técnica do confronto de ideias deveria ser utilizada para contrapor versões e encontrar, um dia, "um esqueleto de verdade" (FOLHA, 1985, p.41). Apesar disso, a afirmação do Projeto Folha é calcada numa leitura da história que fixa um passado "ideal" do jornalismo, que se corrompeu e que deve ser recuperado. Reafirma-se, dessa maneira, a atualidade de tal ideal, insistindo, de certo modo, na atemporalidade da importância de seus valores. Assim, a própria crítica dos jornais da "idade de ouro" é relativizada, retomando para o presente não seus procedimentos, mas seus pressupostos. A partir dos exemplos da Folha de S. Paulo, em 1985, e do Grupo Globo, em 2011, podemos perceber certo desgaste e simultâneo reforço do significante "objetividade", na busca de recuperação de sua atualidade. No caso do jornal paulistano, o termo é retomado na crítica explícita à crítica da objetividade. Já no Grupo Globo, 
temos o reconhecimento de uma certa falência da objetividade enquanto significante e, ao mesmo tempo, uma insistência no seu espectro retórico.

Movendo-nos um pouco no tempo, para agosto de 1945, encontramos no Diário Carioca, considerado por muitos autores um dos protagonistas da modernização da imprensa brasileira (RIBEIRO, 2006 e 2003; BARBOSA, 2007; ALBUQUERQUE, 2010; entre outros), uma pequena coluna intitulada "Cartas a uma foca", cujo subtítulo, bastante explicativo, é: "Numa terra em que todos se julgam jornalistas, eis uma pequena seção para discutir todos os dias os assuntos do jornalismo". Nesta seção, "Joaquim Manoel", provável pseudônimo de Pompeu de Souza (RIBEIRO, 2003), trata de defender alguns elementos e técnicas, principalmente advindas do jornalismo estadunidense, como forma de normatizar conceitos jornalísticos e tarefas da redação. Na edição do dia 08 de agosto, o jornal é enfático em relação ao produto do seu trabalho: "Uma informação é pura e simplesmente uma afirmação". Em seguida, declara que

[d]e certo será impossível e mesmo inviável chegar um jornal à perfeição de dar informações rigorosamente imparciais. Ainda outro dia um observador dessas coisas me chamava a atenção para uma seção que se chama "Dos dois lados" e se ocupa quase sempre de um lado só. Mas sejam ou não "imparciais" elas devem ser "objetivas" (Diário Carioca, 1945, p.4).

É interessante perceber, a partir da citação do Diário Carioca, como o ideal de objetividade entra em voga, neste momento da história, para substituir uma aparentemente desgastada noção de imparcialidade, associada aqui ao tão temido "subjetivismo". Em junho de 1959, O Estado de S.Paulo, por sua vez, lança uma coluna especial, a cargo do jornalista Victor da Cunha Rego, com a finalidade de expor as principais características do jornalismo estadunidense, contrapondo-o ao europeu. Entre elas, por exemplo, o texto destaca a distinção entre a objetividade da notícia e a subjetividade do comentário. Essa clara divisão faz, segundo o jornalista, com que "os profissionais americanos" sejam de "indesmentível honestidade" (REGO, 1959). Nesses dois momentos, do Diário Carioca em 1945 e do Estado de S. Paulo, em 1959 - e ao contrário das imagens delineadas pelo Projeto Folha e pelos Princípios... - o passado é bastante próximo ao presente e deve ser superado, sob o signo da objetividade, para que, no futuro, o jornalismo cumpra efetivamente o papel que lhe foi (auto)atribuído.

Nessas diferentes falas, vocábulos como "imparcialidade", "objetividade" e "honestidade" constituem uma cadeia de substituições em que um termo é usado para renovar o outro e, ao mesmo tempo, afirmar o princípio fundamental ao qual todos respondem: o compromisso jornalístico com os fatos. Essa pequena alteração está em voga também hoje em muitos estudos acadêmicos, cujos autores defendem a substituição do termo "objetividade", por outros a ele associados. Peter Dahlgren (2009) e Dan Gillmor (2005), por exemplo, defendem a ideia de que deveríamos reconhecer 
uma crise contemporânea da noção de objetividade e substituí-la por outras chaves de compressão do jornalismo. O primeiro sugere que o jornalismo adote alguns critérios como a imparcialidade, a transparência, a certeza e a prestação de contas como forma de garantir a qualidade jornalística e superar a ideia clássica de objetividade. Já o segundo defende que esse termo seja substituído por outros como exatidão, justiça e transparência. Em ambos os autores, como se vê, há uma proposta uma alteração de um significante por outros, mantendo-se uma relação especular com a realidade, associada à permanência também de uma concepção de jornalismo. Assim, esses diferentes termos funcionam como significantes vazios, a espera de serem preenchidos discursivamente, para funcionarem na afirmação dessa razão de ser fundamental do jornalismo.

Kevin Barnhurst (2014), em artigo que trata sobre o problema dos eventos realistas no jornalismo estadunidense, afirma que palavras como "verdade" e "fatos" funcionam como espécie de elevador, podendo ser substituídas uma pela outra. Construídas num "mesmo edifício", elas tendem a circular de uma maneira infinita: quando uma começa a falhar, utilizamos a outra, e assim sucessivamente. Acreditamos que algo parecido pode ser dito em relação à flutuação dos termos como objetividade, neutralidade e imparcialidade, evidenciando as contradições nesse jornalismo que advoga, apesar de sua transitoriedade, uma permanência do mesmo.

\section{O presente, seus passados e seus futuros}

Como percebemos a partir de alguns exemplos, o jornalismo tende a fixar sua identidade a partir do que podemos chamar de uma relação de mesmidade (RICOEUR, 2014), baseada na sua vinculação a valores que permaneceriam estáveis. O que acontece quando os jornais têm de lidar com as alterações próprias de sua historicidade, de seu existir atravessado por múltiplas temporalidades (TÉTU, 1993 e 2009; ZELIZER, 2008 e 2009)? Em edições nas quais um jornal apresenta algum tipo de inovação tecnológica ou de modificação em suas estruturas gráficas - ritual recorrente na história do jornalismo -, essa pergunta se torna ainda mais urgente. Afinal, as reformas gráficas e editoriais apontam para mudanças que são, em certa medida, momentos de afirmação do novo, mas também, paradoxalmente, de uma espécie de resistência do jornalismo em relação ao tempo.

É significativo, como já vimos, o modo como essas falas estabelecem relações peculiares com o passado e o futuro. Por um lado, o passado pode ser visto como algo a ser superado, uma vez que é marcado pela inexistência de certos valores fundamentais a serem afirmados. Ou então, pode ser visto como algo a ser, de algum modo, retomado - se não em sua integralidade, pelo menos em sua "essência" -, uma vez que guarda valores que se perderam ou se corromperam. Já o futuro é algo a ser construído - cuidadosamente - pela promoção e legitimação desses mesmos ideais e parâmetros. Vejamos alguns exemplos. Na edição de 14 de março de 2010, o Estadão publica um editorial em que apresenta 
ao público uma nova reforma do jornal. No texto "O que muda e o que permanece", o diário deixa claro essa relação da mesmidade, ao afirmar que as transformações iminentes serão balizadas pelo:

mesmo princípio que norteou as mudanças por que passou o jornal, ao longo dos seus 135 anos de existência: muda a forma, para tornar mais fácil e atraente a leitura, mas permanece inalterado o seu compromisso com a qualidade e a exatidão da informação e com a ética jornalística (O ESTADO, 2010, s/p, grifos nossos).

O jornal formula, portanto, uma promessa de que, apesar das mudanças em seu formato, o seu compromisso com a exatidão da informação não se modifica. Presume-se que as alterações na forma e na textualidade do diário não impactam na informação que ele provê, mantendo "essencialmente" intactos os modos como apreende e conta o mundo. É nesse sentido que o Estadão postula que "nisso não muda, porque faz parte de sua identidade, de sua credibilidade, de seu patrimônio moral" (Idem). Temos aí, portanto, a reafirmação de uma suposta identidade que é sempre a mesma, inalterada apesar das mudanças "aparentes" e das inúmeras narrativas contadas pelo diário ao longo da sua extensa história, que apenas reforçariam ou confirmariam um compromisso original. Essa ideia também está presente numa seção histórica online do Jornal do Commercio. Na página comemorativa, em que se ressalta os seus quase dois séculos de história, temos a seguinte afirmação:

Um diário que não envelhece. Eis o que se pode dizer do Jornal do Commercio, o mais antigo veículo em circulação ininterrupta na América Latina. A primeira edição do jornal, criado pelo francês Pierre Plancher, circulou no dia $1^{\circ}$ de outubro de 1827. Testemunha viva da história, o Jornal do Commercio atravessou as mais diferentes fases do País cumprindo o seu papel de manter informado o público em geral, com a agilidade permitida pela tecnologia de cada época (JORNAL DO COMMERCIO, 2010, s/p).

Um jornal "...que não envelhece" parece ser a proposição de um produto midiático e comunicacional que resiste ao tempo e à história. Interessante notar que, como um agente social destacado no registro dos fatos, o jornal se coloca exatamente como uma testemunha dessa história, que surge assim como um objeto do jornalismo. E isso se dá, significativamente, sem que o jornal seja visto também como um objeto histórico. Há, portanto, a ideia de uma "disponibilidade de história", de um passado circunscrito, delimitado, que se diferenciaria, sobretudo, por causa da "tecnologia de cada época". O presente e o futuro, nesse sentido, surgem e se apagam com uma rapidez cada vez maior, na velocidade que as inovações tecnológicas permitem. Esse argumento também pode ser percebido na apresentação que o Diário Carioca faz das novas instalações de sua redação e gráfica no ano de 1950. Na edição de $1^{\circ}$ de janeiro, há grande destaque para 
a "nova casa do futuro", na qual "em oficinas novíssimas será feito um novo jornal" (DIÁRIO CARIOCA, 1950, p.4). Adjetivos que associam a aceleração do tempo a um projeto de futuro são largamente empregados: "Três pavimentos de máquinas as Mais Modernas para fazer um jornal Moderníssimo - (...) Onde as inovações se casam com um planejamento técnico perfeito. Um passeio entre os 'Colegas de Aço das Oficinas do Futuro" (Idem).

Ao apontar para as mudanças rumo ao futuro, cada mídia informativa que apregoa um compromisso inalterável com os mesmos valores e princípios oferece aos leitores um outro mesmo jornal, melhor e mais moderno, capaz de situar-se frente a uma nova realidade e a um novo tempo, cada vez mais veloz. Nesses casos, a tecnologia funciona como vetor tanto dessa velocidade quanto da transformação que torna possível que o jornal seja novamente o mesmo. Fica clara, portanto, uma concepção do jornalismo que promove a cisão entre forma e conteúdo, o que faz com que seja possível mudar um (o suporte), mantendo-se o compromisso reiterado com qualidade do outro (a informação). Ao mesmo tempo, observa-se que o apelo e a importância da tecnologia promovem ao menos duas inflexões nas contraditórias relações temporais apresentadas nessas falas. Por um lado, as mudanças gráficas, nos modos de impressão, de diagramação, etc. apontam para o progresso, para a evolução, para uma adequação, no presente, às transformações que reconfiguram o futuro. Modernizar-se significa tanto ultrapassar um passado, tecnologicamente atrasado, como atualizar-se. Por outro, a aceleração do tempo "trazida" pelas inovações tecnológicas não deve contaminar ou comprometer a informação, o produto final e decisivo do jornalismo. A modernização, sob o signo do progresso tecnológico, não significa romper com o passado, mas retomá-lo, mesmo como um espaço de experiência idealizado e monumentalizado (MANNA, 2014), como modo de se preservar em relação à desaparição futura.

Os esforços de afirmação no presente, em momentos de transformação, estabelecidos por agentes jornalísticos deixam claros discursos de autolegitimação que, ao afirmar o jornalismo sob o signo do mesmo, organizam, a seu modo, passados e futuros. O apego aos mesmos valores e princípios, por mais imprecisos e flutuantes que sejam, tem como efeito uma imagem do jornalismo como uma atividade à margem da própria história, que se mantém - ou deveria se manter - igual ao longo do tempo. Essa resistência à mudança temporal é acompanhada por uma aparente busca de adequação às transformações em curso, que envolve então imagens peculiares e aparentemente antagônicas do passado e do futuro. Aquilo que passou é mitificado, na forma de "idade de ouro" ou "clássica", e também algo a ser esquecido e superado. Em ambos os casos, se compreendido como espaço de experiência (KOSELLECK, 2006; RICOEUR, 1997), o passado é efetivamente apagado, deixado de lado, submetido ainda a uma ideia de progresso. Já o futuro certamente está ao alcance das mãos, seja porque o jornalismo será sempre o mesmo, seja porque ele pode ser antecipado - atualizado - pelas ações presentes. Como horizonte de expectativa (KOSELLECK, 2006; RICOEUR, 1997), portanto, o futuro é marcado pela 
ideia de continuidade, em que aquilo que é visto como transitório - como a forma e a tecnologia - pode ser absorvido e descartado, na confiança da existência de técnicas e métodos seguros para lidar com a realidade, reduzir subjetivismos, apreender o presente.

\section{Um discurso em questão}

Essas falas dos agentes jornalísticos acerca de si mesmos, recuperadas em diferentes momentos da história brasileira, parecem integrar um discurso mais amplo, recorrente em textos de diferentes modalidades, que busca afirmar e legitimar um modo de ser e entender o jornalismo. Num ensaio dedicado à leitura crítica de consagrados manuais brasileiros de jornalismo -de telejornalismo, particularmente-, Leal (2012) encontra um conjunto de abordagens e entendimentos que são, nesse sentido, bastante esclarecedores. Escritos por jornalistas experientes e voltados para estudantes de comunicação, esses manuais materializariam então um entendimento recorrente acerca do jornalismo. A princípio, os manuais são guiados por uma preocupação descritiva. Significativamente, porém, eles promovem uma passagem fundamental: o tom descritivo é perpassado por um outro, prescritivo, mais forte e predominante. A ideia de "como se faz", que parece guiar esses livros, é complementada pela indicação de "como fazer".

Podemos, nesse sentido, detectar um discurso fortemente normativo, ou seja, um modo de saber e apreender o jornalismo que, para além da experiência histórica da realidade, orienta a maneira como ele deve ser entendido e adotado, afirmando então sua homogeneidade, sua vinculação a certas técnicas e a valores inquestionáveis e imutáveis. Desse modo, chama a atenção o quanto a historicidade dos produtos e processos jornalísticos é "simplificada" no processo de autolegitimação. Nos manuais, a afirmação de um padrão essencial e imutável é acompanhada de uma redução das relações temporais que perpassam os processos e produtos jornalísticos a partir de uma visada evolutiva, calcada no progresso técnico e tecnológico. O "presentismo", assim, parece ser um elemento fundamental no discurso materializado por esses textos de caráter claramente pedagógico e que se constitui sem historicizar ou problematizar valores e experiências.

A semelhança do que dizem esses manuais com as falas "sobre si" dos jornais impressos recuperadas aqui é, nesse sentido, bastante interessante. No esforço de legitimar um modo de fazer jornalismo, manuais e jornais assumem acriticamente os valores do que tomam como padrão, promovendo, sem dúvida alguma, uma espécie de minimização do jornalismo como fenômeno histórico, em suas tensões, diversidades, continuidades e rupturas. Esse tipo de empreendimento, percebido, sobretudo, em livros didáticos (mas não só), tende a oferecer uma história ensimesmada com vistas a encorajar a criação de "heróis de jornalismo, realizadores da história e modelos a serem seguidos no presente e no futuro" (NERONE, 1987, p. 382. No original em inglês). O tom prescritivo, observado por Leal (2012), é frequentemente encontrado em outros textos dedicados ao jornalismo, 
sejam manuais de cunho mais geral, cartas de princípios editoriais e até mesmo em estudos acadêmicos que apregoam a necessidade de uma deontologia jornalística e de critérios fixos e pertinentes para a apreensão da realidade e de sua transposição para as diferentes mídias (Beltrão, 1969; Melo, 2004, 1994; Erbolato, 1988; Lage, 1987, 2002, entre outros). É exatamente esse esforço de legitimar modelos gerais a partir de um "lugar" específico - seja ele uma experiência profissional, uma mídia informativa num dado momento da história ou mesmo um modo de apreendê-lo - que parece unificar o discurso para cujos contornos buscamos encontrar pistas.

$\mathrm{Na}$ fala sobre si dos jornais, especialmente em momentos de reforma editorial, esse esforço de autolegitimação afirma modelos a partir da retomada e ressignificação dos mesmos termos e valores já usados anteriormente (JÁCOME, 2014). Não há, como vimos, propostas efetivas de ruptura, mas de continuidade. Com isso, a afirmação do mesmo se dá na tentativa de apagamento da diversidade presente no fenômeno jornalístico. Afinal, cada jornal, cada notícia, cada produto jornalístico, em seu tempo e em sua história é perpassado por um conjunto de relações e dimensões que os tornam únicos e peculiares. A percepção de recorrências e regularidades certamente não apaga essas singularidades, pois se dá sob as tensões dessa complexidade. Nesse sentido, lidar com a historicidade dos fenômenos, dos produtos e processos jornalísticos é exatamente perceber essas relações complementares e interdependentes de mudança e continuidade, de apagamentos, esquecimentos e retomadas. Assim sendo, ainda que esse discurso de autolegitimação do jornalismo tenda a afirmá-lo como mesmo, é fundamental que se pergunte por que isso se dá e por que se dá desse modo.

No caso dos manuais, o apagamento da história e a opção pelo prescritivo são claramente associados, por um lado, ao propósito didático que os orienta, e, por outro, pela adoção de um "lugar de fala": os seus autores, ao insistirem no que tomam como modelo ou padrão de qualidade para o jornalismo, legitimam a si mesmos como jornalistas, às escolhas que fizeram e aos modos como se inserem - ou se veem inseridos - na profissão. Já no caso dos jornais e organizações empresariais, a permanência em contexto de mudança reitera a suposta identidade assumida para si por cada um deles. Todas essas falas afirmam o mesmo como um modo de se fazer reconhecer, para si e para seus interlocutores, como aquele jornal, que continua e que não é outro - apesar das próprias transformações e descontinuidades. Assim, presente, passado e futuro passam discursivamente a convergir, tendo como eixo o jornal, tal como ele se vê e quer ser visto, num dado momento. É exatamente a identificação com um passado e/ou um futuro projetados como referência que promove essa convergência e afirma a identidade do jornal.

No entanto, essa convergência é conquistada a um custo muito alto. Por um lado, não é apenas o jornal, em suas diversas faces e fases, que convergem para aquele instante de afirmação e mudança: é a própria instituição jornalística, tomada como continuidade dos parâmetros e valores assumidos. Por outro, a diversidade - identitária inclusive - 
do jornal (em suas mudanças e clivagens, como editorias e seções, e nas notícias que apresenta) e do jornalismo (nas várias formas, processos e transformações) é deixada de lado, sacrificada em nome do contínuo aqui-agora. Esse esquecimento de si, referente a uma dada mídia informativa e à instituição social de maneira ampla, promove claros apagamentos e simplificações, além de impor hierarquizações. Por fim, no esvaziamento do espaço de experiência e no encurtamento do horizonte de expectativas, esse discurso autolegitimador e identitário, de tal maneira configurado, não apenas empobrece passados e futuros, mas, no limite, esvazia-se de histórias.

Bruno Souza Leal é professor do departamento de Comunicação Social da UFMG

brunosleal@gmail.com

Nuno Manna é doutor em Comunicação Social pelo PPGCOM UFMG.

nunomanna@gmail.com

Phellipy Jácome é doutorando em Comunicação Social pelo PPGCOM UFMG.

phellipy2002@gmail.com

\section{Referências}

ALBUQUERQUE, A.; A modernização autoritária do jornalismo brasileiro. Revista Alceu, v. 10, n. 20, p. 100-115. Rio: PUCRJ, 2010.

ANTUNES, E. e VAZ, P. Mídia: um halo, um aro, um elo. In: FRANÇA, V. e GUIMARÃES, C. (Orgs.). Narrativas do cotidiano, p. 43-60. Belo Horizonte: Autêntica, 2006.

BARNHURST, K.G. The Problem of Realist Events in American Journalism. In: Media and Communication. Vol. 2, n. 2, p. 84-95. Lisboa: Cogitatio Press, 2014.

BELTRÃO, L. Iniciação à filosofia do jornalismo. Rio de Janeiro: Agir, 1969.

BRAGA, J. L. Comunicação, disciplina indiciária. In: MATRIZes, vol. 1, n. 2, p. 73-88. São Paulo: USP, 2009.

COSTA, H. J. da. Correio Braziliense ou Armazém literário. São Paulo: Imprensa Oficial do Estado; Brasília: Correio Braziliense, 2001-2003.

DAHLGREN, P. The Troubling Evolution of Journalism. In: ZELIZER, Barbie (org.). The Changing Faces of Journalism: Tabloidization, Technology and Truthiness, p 146-160. Nova York: Routledge, 2009.

FOLHA DE S. PAULO. Espelho do Mundo (Editorial). Folha de S. Paulo, p. A-2. São Paulo, 23 mai. 2010. 
FOLHA DE S. PAULO. Novo Manual da Redação. São Paulo: Folha de S. Paulo, 1993.

FRIAS Fo, O. A Crítica da Crítica da Objetividade. In: Folha de S. Paulo, 27 jun. 1985, p. 41. São Paulo: Folha de S. Paulo, 1985.

GILLMOR, D. The End of Objectivity. Dan Gillmor on Grassroots Journalism, Etc., 20 jan. 2005. Disponível em <http://dangillmor.typepad.com/dan_gillmor_on_grassroots/2005/01/the_end_of_obje. html> Acesso em: 8/12/2016.

GINZBURG, C. Mitos, emblemas, sinais: morfologia e historia. São Paulo: Companhia das Letras, 1990.

GRUPO GLOBO. Princípios Editoriais do Grupo Globo. Site G1. Rio de Janeiro, 2011. Disponível em <http://g1.globo.com/principios-editoriais-do-grupo-globo.html>. Acesso em: 8/12/2016.

HOHLFELDT, A. C.; OLIVEIRA, S. M. Conceitos sobre jornalismo no Correio Braziliense (O ano de 1809). In: XVII Encontro Nacional da Compós, 2008, São Paulo. Anais do Encontro Anual da Compós. São Paulo: COMPOS, 2008.

JÁCOME, P. Jornalismo e Autolegitimação: a Historicidade dos Discursos Autorreferentes. In: Leituras do Jornalismo, n.2, p. 54-66. Bauru: FAAC-Unesp, 2014. Disponível em <http://www2.faac.unesp. br/ojs/index.php/leiturasdojornalismo/article/view/31>. Acesso em: 12/12/2016.

KARAM, F. J. C. Curso de Formação e ética jornalística. Brasília: Fenaj, 2001. Disponível em <http:// www.gersonmartins.jor.br/dados/aulas/turma1/formacao_eticajornalistica_karam\%5B8\%5D.pdf >. Acesso em: 12/12/2016.

KOSELLECK, R. Futuro passado: contribuição à semântica dos tempos históricos. Rio de Janeiro: Contraponto/Ed. PUC-Rio, 2006.

LAGE, N. A estrutura da notícia. São Paulo: Ática, 1987.

Linguagem jornalística. São Paulo: Ática, 2002.

LEAL, B. S. Do texto ao discurso: as normas sem história dos manuais de telejornalismo. In: GOMES, Itania (Org.). Análise do telejornalismo: desafios teórico-metodológicos, p. 117-142. Salvador: EdUFBA, 2012.

LATOUR, B. Jamais Fomos Modernos. São Paulo: Editora 34, 1994

MANNA, N. Reverência a um paradigma em crise: história monumental do jornalismo nos EUA. In: Revista Brasileira de História da Mídia, v. 4, p. 21-30. São Paulo: Alcar, 2014.

MELO, J. M. de. A opinião no jornalismo brasileiro. Petrópolis: Vozes, 1994.

. A esfinge midiática. São Paulo: Paulus, 2004.

MOUILLAUD, M. Da Forma ao Sentido. In: PORTO, Sérgio Dayrell (Org.). O Jornal: da Forma ao Sentido. Brasília: UnB, 2002.

NERONE, J. The Mythology of the Penny Press. In: Critical Studies in Mass Communication, Vol. 4, Ed. 4, p. 376-404. Salt Lake City (EUA): University of Utah, 1987. Disponível em <HTTP://DX.DOI. ORG/10.1080/15295038709360146>. Acesso em: 12/12/2016.

RIBEIRO, A.P.G. Memória de Jornalista: um estudo sobre o conceito de objetividade nos relatos dos homens de imprensa dos anos 50. Rio de Janeiro: Compós, 2003.

Imprensa e História no Rio de Janeiro dos anos 50. Rio de Janeiro: E-papers Ed., 2007.

RICOEUR, Paul. Tempo e Narrativa. Tomo III. Campinas: Papirus, 1997.

O Si-mesmo como Outro. 1.ed. São Paulo: WMF Martins Fontes, 2014. 
TÉTU, Jean-François. L'actualité ou l'impasse du temps. In: SCIENCES de I'Information et de la Communication: textes essentiels, p. 713-722. Paris: Larousse, 1993.

. Les medias et les temps. In: VITALIS, A.;TÉTU, J-F.; e PALMER, M. (Eds.). Médias, temporalités et démocratie. Págs. 91-108. Rennes (FRA): Ed. Apogée, 2002. Disponível em <http://halshs.archivesouvertes.fr/docs/00/39/62/71/PDF/tetu_temporalite.pdf>. Acesso em: 12/12/2016.

VOS, Tim P. A Mirror of the Times. In: Journalism Studies, Vol. 12, N. 5, págs. 575-589. London: Routledge, 2011.

ZELIZER, Barbie (org.). Explorations in communication and history. Nova York: Routledge, 2008.

The Changing Faces of Journalism: Tabloidization, Technology and Truthiness. New York: Routledge, 2009.

Artigo recebido em setembro e aprovado em novembro de 2016. 